\title{
STUDI KOMPARASI ANTARA MODEL PEMBELAJARAN DISCOVERY LEARNING DAN GROUP INVESTIGATION TERHADAP HASIL BELAJAR KIMIA SISWA
}

\author{
Julita Sari $^{* 1}$, Amrul Bahar ${ }^{2}$, Dewi Handayani ${ }^{3}$ \\ Jurusan Pendidikan MIPA Fakultas Keguruan dan Ilmu Pendidikan Universitas Bengkulu \\ ${ }^{1,2,3}$ Pendidikan Kimia, Jurusan PMIPA, FKIP, Universitas Bengkulu \\ e-mail : julitasari26@gmail.com
}

\begin{abstract}
The average students' chemical learning outcomes are still low, the low learning outcome is influenced by several factors, including students still consider that chemistry as one of the scary, difficult to understand and less interesting lessons. Therefore, the research wants to vary the learning process in the classroom by applying the learning model of Discovery Learning with Group Investigation model. This research was aimed to find out the students' achievement differences of chemical subject by using Discovery learning and Group Investigation model. The research is quasi experimental research. The population of this research were class X MIPA in SMAN 9 Bengkulu City, and the sample were X MIPA 2 and MIPA 3. This research using two experimental classes, that is class X MIPA 2 applying Group Investigation model and X MIPA 3 applying Discovery Learning model. Analysis of the data used is mean values, normality test, homogeneity test, and t-test. Post-test mean values for first experiment class is 78,12 , but for second experiment class is 81,3 . To determine whether the differences of student's learning outcomes between both of experiment classes or not, we use t-test by using the differences between student's pretest and posttest values, $\mathrm{t}_{\text {count }}>\mathrm{t}_{\text {table }}(2,17>1,67)$. The result of this research showed that Ha accepted, in other words is a significant differences in learning outcomes of student's applying Discovery Learning and Group Investigation model.
\end{abstract}

Keywords: Discovery Learning , Group Investigation, Achievement

\begin{abstract}
Abstrak
Rata-rata hasil belajar kimia siswa masih rendah, rendahnya hasil belajar ini dipengaruhi oleh beberapa faktor, di antaranya siswa masih menganggap bahwa kimia sebagai salah satu pelajaran yang menakutkan, sulit dipahami dan kurang menarik. Oleh sebab itu penelitian ingin memvariasikan proses pembelajaran di kelas dengan menerapkan model pembelajaran Discovery Learning dengan model Group Investigation. Penelitian ini bertujuan untuk mengetahui perbedaaan hasil belajar siswa menggunakan model pembelajaran Discovery Learning dengan model Group Investigation. Jenis penelitian yang digunakan adalah penelitian eksperimen dengan populasi kelas X MIPA di SMAN 9 Kota Bengkulu dan sampel adalah kelas X MIPA 2 yang menerapkan model pembelajaran Group Investigation dan kelas X MIPA 3 yang menerapkan model Discovery Learning. Analisa data yang digunakan adalah nilai rata-rata, uji normalitas, uji homogenitas, dan uji t. Berdasarkan nilai posttest kedua kelas eksperimen, diketahui nilai rata-rata posttest kelas eksperimen I adalah 78,12 sedangkan untuk kelas eksperimen II adalah 81,3. Untuk mengetahui ada atau tidaknya perbedaan hasil belajar siswa pada kedua kelas eksperiman maka dilakukan uji t dan diperoleh $t_{\text {hitung }}>t_{\text {tabel }}(2,17>1,67)$. Hasil penelitian ini menunjukkan bahwa Ha diterima dengan kata lain terdapat perbedaan yang signifikan dari hasil belajar siswa antara yang menerapkan model pembelajaran Discovery Learning dan Group Investigation.
\end{abstract}

Kata kunci ; Discovery Learning ,Group Investigation, Hasil Belajar

\section{PENDAHULUAN}

Pendidikan merupakan suatu wadah penting yang mempengaruhi potensi manusia dan menjadi salah satu faktor penting bagi suatu bangsa karena menjadi tolak ukur kemajuan bangsa tersebut [1]. Pendidikan adalah usaha sadar dan terencana untuk peserta didik secara aktif mengembangkan potensi dirinya untuk memiliki kekuatan spiritual keagamaan, pengendalian diri, kepribadian, kecerdasan, akhlak mulia, serta keterampilan yang diperlukan dirinya, masyarakat, bangsa dan negara [2].

Pada saat ini sistem pendidikan di Indonesia menggunakan Kurikulum 2013, yang tidak hanya berorientasi terhadap hasil dan materi kependidikan me- lainkan juga memperhatikan proses [3], mengamanatkan penggunaan pendekatan ilmiah (scientific appro$a c h$ ) yang menonjolkan dimensi pengamatan, penalaran, penemuan, pengabsahan, dan penjelasan mengenai suatu kebenaran [4], sehingga diharapkan proses transfer ilmu dan pengetahuan di sekolah dapat ditingkatkan agar kualitas dan hasil pembelajaran diharapkan dapat memenuhi tujuan yang telah ditetapkan [5].

Berdasarkan hasil wawancara dengan guru mata pelajaran kimia di SMAN 9 Kota Bengkulu, diketahui bahwa rata-rata hasil ujian semester 1 mata pelajaran kimia kelas X MIPA masih belum mencapai KKM kriteria ketuntasan minimal (KKM), yaitu 75, antara lain karena pemahaman konsep kimia yang dimiliki siswa masih rendah. Salah satu upaya untuk mem- 
perbaiki kualitas proses pembelajaran, yaitu dengan mengadakan variasi dalam kegiatan belajar mengajar di kelas dengan menerapkan model pembelajaran yang menekankan pada proses pembelajaran siswa aktif. Salah satunya adalah model pembelajaran discovery learning (DL) dan group investigation (GI).

Discovery learning adalah belajar mencari, menyelidiki dan menemukan sendiri dan merupakan proses mental siswa mengasimilasikan suatu konsep atau suatu prinsip. [6] dengan mempergunakan teknik pendekatan pemecahan masalah, sehingga hasil yang diperoleh akan setia dan tahan lama dalam ingatan, [7] dengan memperluas peran siswa untuk mengumpulkan informasi tentang materi, mengorganisasikannya, serta membuat kesimpulan-kesimpulan [8]. Model ini memiliki beberapa kelebihan, yaitu dapat meningkatkan kemampuan memecahkan masalah, melatih belajar mandiri, menguatkan pengertian, ingatan, dan transfer, serta dapat membuat siswa aktif dalam kegiatan belajar mengajar untuk menemukan hasil akhir [9]. Model discovery learning banyak memberikan kesempatan bagi para anak didik untuk terlibat langsung dalam kegiatan belajar, sehingga akan lebih membangkitkan motivasi belajar serta disesuaikan dengan minat dan kebutuhan mereka sendiri. [10].

Model pembelajaran group investigation merupakan model pembelajaran kooperatif yang paling kompleks dan paling sulit untuk diterapkan, siswa terlibat dalam perencanaan baik topik yang dipelajari dan bagaimana jalannya penyelidikan mereka, sehingga memerlukan norma dan struktur kelas yang lebih rumit daripada pendekatan yang berpusat pada guru [11]. Siswa dilibatkan sejak perencanaan, baik dalam menentukan topik maupun cara untuk mempelajarinya melalui investigasi, sehingga menuntut para siswa untuk memiliki kemampuan yang baik dalam berkomunikasi maupun keterampilan proses kelompok [12].

Model pembelajaran koorperatif tipe group investigation mampu melibatkan peran aktif siswa sehingga akan mempermudah siswa dalam memahami materi yang dipelajari dan pembelajaran akan berlangsung dalam komunikasi multi arah. Pembelajaran ini mampu mengajak siswa untuk menemukan dan memperoleh konsep materi itu sendiri [13].

Dalam implementasinya, guru membagi kelas menjadi kelompok-kelompok dengan anggota 5-6 siswa yang heterogen. dengan mempertimbangkan keakraban persahabatan atau minat yang sama dalam topik tertentu untuk diselidiki, melakukan penyelidikan mendalam atas topik yang dipilih. Selanjutnya ia menyiapkan dan mempresentasikan laporannya kepada seluruh kelas [15]. Kelebihan dari model ini yaitu dapat melatih siswa untuk memiliki kemampuan yang baik dalam berkomunikasi dan mengemukakan pendapatnya, memotivasi dan mendorong siswa agar aktif mulai dari tahap pertama sampai tahap akhir pembelajaran, sehingga suasana belajar akan lebih efektif, membangkitkan semangat untuk berani dalam mengemukan pendapat dan berbagi informasi [16].

Berlatar dari masalah diatas, penulis hendak melakukan penelitian dengan tujuan untuk mengetahui hasil belajar siswa yang menerapkan model pembelajaran discovery learning (DL), dan group investigation (GI), di kelas X MIPA SMA Negeri 9 Kota Bengkulu T.P 2016/2017 serta mengetahui perbedaan yang ada antara hasil belajar untuk masing masing model .

\section{METODE PENELITIAN}

Penelitian ini menggunakan metode eksperimen semu. Penelitian ini dilaksanakan pada bulan MaretApril 2017, di SMAN 9 Kota Bengkulu. Populasi dalam penelitian ini adalah siswa kelas X MIPA SMA Negeri 9 Kota Bengkulu tahun pelajaran 2016/2017 yang berjumlah 4 kelas. Pengambilan sampel dilakukan secara simple random sampling yang sebelumnya telah dilakukan uji homogenitas terhadap populasi. Sampel yang terpilih adalah siswa kelas X MIPA 2 sebagai kelas eksperimen I yang diberi perlakuan model Group Investigation dan X MIPA 3 sebagai kelas eksperimen II diberi perlakuan model Discovery Learning. Variabel yang digunakan dalam peneliian ini yaitu variabel bebas adalah model pembelajaran Discovery learning (DL) dan model pembelajaran Group investigation (GI). Dan variabel terikat pada penelitian ini adalah hasil belajar kimia siswa pada pokok bahasan hukum-hukum dasar kimia. Teknik pengumpulan data dilakukan dengan menggunakan instrumen tes uraian untuk mengukur prestasi belajar aspek kognitif. Teknik analisis data terdiri atas uji prasyarat analisis dan uji hipotesis. Uji prasyarat analisis meliputi nilai rata-rata (mean), uji normalitas dan uji homogenitas, dan uji hipotesis menggunakan uji-t.

\section{HASIL DAN PEMBAHASAN}

Data yang diperoleh pada penelitian ini berupa hasil belajar kimia siswa antara kelas X MIPA 2 sebagai kelas eksperimen I yang menggunakan model Group Investigation dan kelas X MIPA 3 sebagai kelas eksperimen II yang menggunakan model Discovery Learning yang diambil secara acak dari populasi yang telah diuji homogenitas sebelumnya. Sebelum diberikan perlakuan kedua kelas diberikan pretest untuk mengetahui keadaan awal dari kelas eksperimen I dan kelas eksperimen II dan diberikan posttest diakhir proses pembelajaran. Data tersebut dapat dilihat pada Tabel 1 berikut ini : 
Tabel 1. Rekapitulasi Nilai Kelas Eksperimen I dan Eksperimen II

\begin{tabular}{ccc}
\hline Komponen & $\begin{array}{c}\text { Kelas } \\
\text { Eksperimen } \\
\text { I }\end{array}$ & $\begin{array}{c}\text { Kelas } \\
\text { Eksperimen } \\
\text { II }\end{array}$ \\
\hline $\begin{array}{c}\text { Rata-rata } \\
\text { pretest }\end{array}$ & 20,67 & 16,5 \\
\hline $\begin{array}{c}\text { Rata-rata } \\
\text { posttest }\end{array}$ & 78,12 & 81,3 \\
\hline $\begin{array}{c}\text { Rata-rata } \\
\text { selisih } \\
\text { pretest } \text { dan } \\
\text { posttest }\end{array}$ & 57,45 & 64,83 \\
\hline $\begin{array}{c}\text { Standar } \\
\text { deviasi }\end{array}$ & 12,18 & 13,94 \\
\hline $\begin{array}{c}\text { N (jumlah } \\
\text { siswa) }\end{array}$ & 30 & 30 \\
\hline Varians & 148,35 & 194,36 \\
\hline
\end{tabular}

Berdasarkan hasil pretest, diketahui bahwa nilai rata-rata kelas yang menerapkan model pembelajaran Group Investigation sebesar 20,67 dan kelas yang menerapkan model pembelajaran Discovery Learning sebesar 16,5. Berdasarkan hasil tersebut menunjukkan bahwa pengetahuan awal siswa pada kedua kelas eksperimen terhadap materi yang akan dipelajari masih kurang, dikarenakan siswa tidak memiliki persiapan yang baik sebelum pembelajaran dilaksanakan, sehingga belum mampu mengerjakan soal pretest dengan baik. Berdasarkan data yang diperoleh dari hasil posttest diketahui nilai rata-rata kedua kelas, dimana kelas yang menerapkan model pembelajaran Group Investigation sebesar 78,12 dan kelas yang menerapkan model pembelajaran Discovery Learning sebesar 81,3. Setelah dilakukan pretest dan posttest dari kedua kelas diperoleh peningkatan hasil belajar siswa dari kedua kelas eksperimen dimana peningkatan diketahui dari Gambar 1 berikut ini:

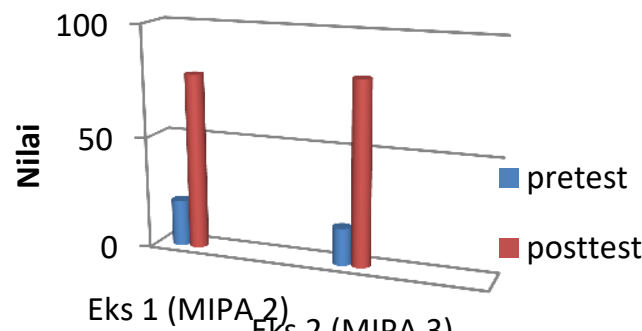

Kelas Eksperimen

\section{Gambar 1. Rata-Rata Nilai Siswa}

Berdasarkan Gambar 1 di atas dapat dilihat terdapat kenaikan nilai rata-rata hasil belajar kimia siswa yang menerapkan model pembelajaran Group
Investigation yaitu pada kelas eksperimen I dan hasil belajar kimia siswa yang menerapkan model pembelajaran Discovery Learning yaitu pada kelas eksperimen II. Dari penerapan kedua model pembelajaran tersebut dapat disimpulkan bahwa kedua model tersebut sama-sama cukup baik untuk diterapkan pada proses pembelajaran di kelas. Hal ini terlihat dari ratarata nilai posttest dari kelas eksperimen I maupun kelas eksperimen II yang sudah mencapai nilai diatas KKM. Penerapan model pembelajaran Group Investigation dan Discovery Learning memiliki pola yang ham-pir sama yaitu menekankan pada proses pembe-lajaran siswa aktif dimana siswa diarahkan untuk mencari atau menemukan sendiri informasi mengenai topik yang dipelajari dan guru hanya berperan sebagai fasilitator atau membimbing siswa pada proses belajarnya.

Model pembelajaran Group Investigation cukup baik diterapkan dikarenakan model ini menuntut siswa untuk berpartisipasi aktif saat berdiskusi bersama anggota kelompoknya, serta memungkinkan siswa bekerja sama dan bertukar ide serta berani mengemukakan pendapatnya sehingga memberikan kesempatan berpartisipasi yang lebih besar bagi setiap anggota dan merasa terlibat terhadap belajarnya. Pada proses pembelajarannya siswa juga berpikir bersama memecahkan tugasnya, membelajarkan antar anggota untuk memahami materinya, serta menyiapkan diri untuk mempresentasikan hasil diskusi mereka. Sehingga setiap siswa harus memiliki tanggung jawab yang besar terhadap dirinya sendiri maupun terhadap kelompoknya.

Pada penerapan model pembelajaran Discovery Learning juga cukup baik diterapkan, model ini membantu siswa untuk belajar sendiri dan menerapkan apa yang diketahui pada situasi baru sehingga menyebabkan terjadinya pembelajaran yang efektif, siswa menjadi lebih aktif menemukan sendiri suatu konsep, sehingga konsep yang dihasilkan mudah diingat dan tertanam lebih lama di dalam pikiran. Siswa diarahkan untuk menghubungkan pengetahuan yang sudah ada ke dalam situasi yang baru sehingga konsep dapat terbentuk dengan baik. Penerapan model Discovery Learning yang diperoleh juga sesuai dengan hasil penelitian yang dilakukan sebelumnya yang menunjukkan bahwa penerapan model pembelajaran Discovery Learning dapat meningkatkan prestasi belajar aspek kognitif $63,00 \%$ pada siklus I meningkat menjadi $81,00 \%$ pada siklus II [17].

Selain kelebihan-kelebihan pada penerapan kedua model pembelajaran tersebut, dalam pelaksanaannya pun tidak luput dari beberapa kendala, seperti pada saat proses pembelajaran baik model Group Investigation maupun model Discovery Learning menyita banyak waktu jika dibandingkan dengan model pembelajaran konvensional, karena guru dituntut mengubah kebiasaan mengajar yang umumnya sebagai 
pemberi informasi menjadi fasilitator, motivator, dan pembimbing.

Setelah nilai rata-rata selisih dari kedua kelas diketahui, maka dilakukan uji normalitas. Menggu-nakan uji chi kuadrat (chi square) dengan taraf signifikansi $0,01(1 \%)$. Berdasarkan perhitungan yang telah dilakukan, diperoleh hasil $\mathrm{X}^{2}{ }_{\text {hitung }}$ untuk kedua kelas eksperimen yaitu seperti pada Tabel 2 berikut ini:

Tabel 2. Hasil Uji Normalitas

\begin{tabular}{cccc}
\hline No & Data & $\begin{array}{c}\text { Model Group } \\
\text { Investigation }\end{array}$ & $\begin{array}{c}\text { Model } \\
\text { Discovery } \\
\text { Learning }\end{array}$ \\
\hline 1 & $\begin{array}{c}\mathrm{X}^{2} \\
\text { hitung }\end{array}$ & 8,64 & 5,07 \\
\hline 2 & $\mathrm{X}^{2}$ tabel & 11,3 & 11,3 \\
\hline
\end{tabular}

Berdasarkan data dari Tabel 2 di atas dapat dike-tahui bahwa pada kedua kelas eksperimen baik yang menggunakan model Group Investigation dan model Discovery Learning memperoleh nilai $\mathrm{X}_{\text {hitung }}^{2}<\mathrm{X}_{\text {tabel. }}^{2}$ Maka dari itu dapat disimpulkan bahwa kedua kelas eksperimen terdistribusi normal. Adapun hasil perhitungan untuk uji homogenitas pada kedua kelas eksperimen, diperoleh hasil sebagai berikut:

Tabel 3. Hasil Uji Homogenitas

\begin{tabular}{ccc}
\hline No & Data & Hasil Perhitungan \\
\hline 1. & F $_{\text {hitung }}$ & 1,31 \\
\hline 2. & F $_{\text {tabel }}$ & 4,13 \\
\hline
\end{tabular}

Dari Tabel 3 dapat dilihat bahwa $\mathrm{F}_{\text {hitung }}<\mathrm{F}_{\text {tabel }}$ $(1,31<4,13)$, dimana apabila $F_{\text {hitung }}<F_{\text {tabel }}$ maka kedua kelas eksperimen mempunyai varians yang homogen.

Selanjutnya dilakukan uji hipotesis menggunakan uji t pada taraf signifikan $1 \%(0,01)$. Dari hasil uji $\mathrm{t}$ diperoleh hasil pada tabel 4 berikut ini:

Tabel 4 Hasil Uji Hipotesis

\begin{tabular}{lcc}
\hline No & Nilai & Hasil Perhitungan \\
\hline 1. & $\mathrm{t}_{\text {hitung }}$ & 2,17 \\
\hline 2. & $\mathrm{t}_{\text {tabel }}$ & 1,67 \\
\hline
\end{tabular}

Berdasarkan perhitungan uji t, diperoleh hasil bahwa nilai $t_{\text {hitung }}>t_{\text {tabel }}$, maka dapat disimpulkan bahwa hipotesis alternatif $\left(\mathrm{H}_{\mathrm{a}}\right)$ diterima, ini berarti terdapat perbedaan yang signifikan dari hasil belajar kimia siswa pada kelas yang menerapkan model pembelajaran Discovery Learning dengan kelas yang menerapkan model pembelajaran Group Investigation pada pokok bahasan hukum-hukum dasar kimia. Dimana penerapan model pembelajaran Discovery Learning lebih baik jika dibandingkan dengan penerapan model pembelajaran, yang terlihat dari rata-rata selisih nilai pretest dan posttest kelas Discovery Learning lebih tinggi jika dibandingkan rata-rata kelas Group Investigation $(64,83>57,46)$. Hal ini dikarenakan pada penerapan model pembelajaran Discovery Learning siswa dalam kelompoknya masing-masing mempelajari semua subtopik materi dibantu dengan adanya lembar diskusi siswa (LDS), sedangkan pada penerapan model Group Investigation masing-masing kelompok membahas satu subtopik yang berbeda antar kelompok sehingga menyebabkan masing-masing kelompok rata-rata lebih memahami sub topik yang mereka kerjakan, walaupun pada proses pembelajarannya tiap kelompok bertanggung jawab untuk menjelaskan topik yang mereka kerjakan ke kelompok lain. Hal ini sesuai dengan hasil penelitian sebelumnya yang menunjukkan bahwa penerapan model pembelajaran Group Investigation dapat meningkatkan prestasi belajar yang terlihat dari ketuntasan belajar siswa meningkat dari $30,56 \%$ pada siklus I menjadi 91,67\% pada siklus II [18].

Pada proses pembelajaran model Group Investigation waktu yang dibutuhkan siswa untuk belajar kurang efektif dikarenakan siswa lebih mandiri untuk merencanakan sendiri apa yang akan mereka selidiki pertopik hingga mempresentasikannya di depan kelas, yang menyebabkan waktu yang dibutuhkan lebih panjang. Sedangkan pada model Discovery Learning, siswa bersama kelompoknya dibagikan LDS sehingga para siswa mempunyai pedoman bagaimana mereka akan mempelajari materi yang dipelajari, yang mengakibatkan waktu yang digunakan lebih efektif.

\section{KESIMPULAN}

Hasil belajar siswa yang menerapkan model pembelajaran Discovery Learning diperoleh nilai ratarata pretest 16,5 dan nilai rata-rata posttest 81,3 dengan selisih nilai rata-rata pretest dan posttest yaitu 64,83 .

Hasil belajar siswa yang menerapkan model pembelajaran Group Investigation diperoleh nilai ratarata pretest 20,67 dan nilai rata-rata posttest 78,12 dengan selisih nilai rata-rata pretest dan posttest yaitu 57,45 .

Terdapat perbedaan yang signifikan antara hasil belajar siswa yang menerapkan model pembelajaran Discovery Learning dengan yang menerapkan model pembelajaran Group Investigation, yang ditun- 
jukkan dengan nilai $t_{\text {hitung }}(2,17)$ lebih besar dari pada nilai $t_{\text {tabel }}(1,67)$.

\section{SARAN}

Pada model pembelajaran Group Investigation sebaiknya semua siswa dalam satu kelompok memiliki sumber materi lebih banyak selain dari buku referensi yang berasal dari guru.

Pada kegiatan pembelajaran Group Investigation, perlu adanya kerjasama yang baik antara siswa dan guru, waktu yang cukup, siswa yang bisa diajak kerjasama sehingga pembelajaran dapat dilakukan dengan baik, dan mampu untuk mengatur siswa yang ribut dan kurang serius dalam proses pembelajaran.

Pada pembelajaran model Discovery Learning sebaiknya guru mencoba terlebih dahulu proses pembelajaran seperti ini kepada kelas uji coba agar meminimalisir kebingungan siswa yang tidak biasa melaksanakan proses pembelajaran dengan model Discovery Learning.

\section{UCAPAN TERIMA KASIH}

Terima kasih kepada Kepala Sekolah, Guru Kimia dan segala pihak di SMA Negeri 9 Kota Bengkulu yang telah membantu dalam menyelesaikan penelitian ini

\section{DAFTAR PUSTAKA}

[1] Widyastono, 2014, Pengembangan Kurikulum di Era Otonomi Daerah, Bumi Aksara, Jakarta.

[2] Prasetyowati, Soekristin, 2013, Penerapan Model Pembelajaran Group Investigation (GI) Dalam Upaya Peningkatan Aktivitas Dan Prestasi Bela-jar Kimia Pada Materi Sistem Tata Nama Senyawa Hidrokarbon, Seminar Nasional Kimia dan Pendidikan Kimia V, Surakarta, 6 April 2013.

[3] Mulyasa, 2014, Pengembangan dan Implementasi Kurikulum 2013, Remaja Rosdakarya, Bandung, ISBN: 978-979-629-447-9.

[4] Ayadiya, Naila, 2014, Penerapan Model Pembelajaran Discovery Learning Dengan Scientific Approach Untuk Meningkatkan Keterampilan Proses Sains Siswa SMA, Skripsi, Program Studi Pendidikan Kimia, Univ. Negeri Semarang, http://lib.unnes.ac.id/ 23161/ 1/4301410015.pdf.

[5] Sukmawati, Agustina, Widiastuti, Agustina, E.S. dan Sri, Yamtinah, 2016, Studi Komparasi Model Group Investigation (GI) dan Problem Solving Terbimbing Dilengkapi Lembar Kerja Siswa (LKS) Terhadap Prestasi Belajar Dengan Memperhatikan Kemampuan Matematik Siswa Pada Materi Pokok Kelarutan dan Hasil Kali
Kelarutan Kelas XI SMA Negeri 1 Karanganyar Tahun Ajaran 2015/2016, Jurnal Pendidikan Kimia ,3(5): 45-53.

[6] Vahlia, Ira dan Rina, Agustina, 2016, Perbandingan Hasil Belajar Discovery Learning Berbasis Problem Solving dan Group Investigation Berbasis Problem Solving Pada Pembelajaran Metode Numerik, Jurnal Pendidikan Matematika FKIP Univ. Muhammadiyah Metro,1(5): 82-93.

[7] Asril, Zainal, 2013, Micro Teaching Disertai dengan Pedoman Pengalaman Lapangan, Raja Grafindo Persada, Jakarta. ISBN: 978-979-769291-9.

[8] Yurmawita, 2016, Pengelolaan Pembelajaran Matematika Dengan Pendekatan Discovery Learning Pada Siswa MA, Jurnal Ilmiah Manajemen Pendidikan, 10(4):407-410.

[9] Hosnan, 2014, Pendekatan Saintifik Dan Kontekstual Dalam Pembelajaran Abad 21: Kunci Sukses Implementasi Kurikulum, Ghalia Indonesia, Bogor, ISBN: 978-979-450-683-7.

[10] Rosarina, Gina, Ali, Sudin, dan Atep, Sujana, 2016, Penerapan Model Discovery Learning Untuk Meningkatkan Hasil Belajar Siswa Pada Materi Perubahan Wujud Benda, Jurnal Pena Ilmiah, 1(1): 371-380.

[11] Uno, Hamzah.B. dan Nurdin Mohamad, 2011, Belajar dengan Pendekatan PAILKEM, Bumi Aksara, Jakarta, ISBN: 978-602-217-127-0.

[12] Rauzana, 2011, Penerapan Model Pembelajaran Kooperatif Tipe Group Investigation (GI) Untuk Meningkatkan Prestasi Belajar Siswa Pada Pokok Bahasan Hirokarbon dan Minyak Bumi Di Kelas X Madrasah Aliyah Al- Muttaqien Kecamatan Bunga Raya Kabupaten Siak, Skripsi, Fakultas Tarbiyah dan Keguruan, Universitas Islam Negeri Sultan Syarif Kasim Riau, Pekanbaru, http://repository.uin-suska. ac.id/1366/1/2011_2011588.pdf

[13] Maynastiti, Dewi, Vina, Serevina, Anggara, dan Budi, Susila, Oktober 2015, Perbandingan Hasil Belajar Fisika Siswa Yang Menggunakan Model Pembelajaran Koorperatif Tipe Group Investigation dengan Discovery Inquiry di SMA, Prosiding Seminar Nasional Fisika, Jakarta.

[14] Trianto, 2010, Mendesain Model Pembelajaran Inovatif-Progresif, Kencana, Jakarta, ISBN: 978-979-1486-68-2.

[15] Fathurrohman, Muhammad, 2015, Paradigma Pembelajaran Kurikulum 2013, Kalimedia, Yogyakarta, ISBN: 978-602-730-138-2.

[16] Istiana, G.A, Saputro, A.N.C, Sukardjo, J.S, , 2015, Penerapan Model Pembelajaran Discovery Learning Untuk Meningkatkan Aktivitas Dan Prestasi Belajar Pokok Bahasan Larutan 
Penyangga Pada Siswa Kelas XI IPA Semester II SMA Negeri 1 Ngemplak Tahun Pelajaran 2013/2014. Jurnal Pendidikan Kimia, 4(2):, ISSN: 2337-9995.

[17] Ciptaningtyas, A.N, Haryono, Masykuri, M. , 2014, Model Pembelajaran Group Investigation (GI) Dilengkapi Media Peta Pikiran Pada Materi Pokok Kelarutan dan Hasil Kali Kelarutan Untuk Meningkatkan Kerjasama dan Prestasi Belajar Siswa Kelas XI IPA SMA Negeri Kebakkramat Tahun Pelajaran 2012/2013. Jurnal Pendidikan Kimia, 3(2). ISSN: 2337-9995.
Penulisan Sitasi Artikel ini ialah :

Sari, J, Bahar, A., Handayani, D. 2017. Studi Komparasi Antara Model Pembelajaran Discovery Learning dan Group Investigation Terhadap Hasil Belajar Kimia Siswa, Alotrop, 1(1):60-65. 